\title{
ESTUDO DA HIDRÓLISE ENZIMÁTICA DA PALHA DA CANA DE AÇÚCAR PARA PRODUÇÃO DE ETANOL DE SEGUNDA GERAÇÃO
}

\author{
A. C. LUCARINI ${ }^{1, *}$, A. C. T. DELQUIARO ${ }^{1}$, L. C. P. T. VIDOCA ${ }^{1}$, R. BRAZ ${ }^{1}$, \\ R. M. MARTINS ${ }^{1}$, T. P. ALVES ${ }^{1}$ \\ ${ }^{1}$ Centro Universitário FEI, Departamento de Engenharia Química \\ *E-mail: lucarini@fei.edu.br
}

\begin{abstract}
RESUMO: Estudou-se a hidrólise enzimática da palha da cana para a obtenção de açúcares fermentescíveis. A palha passou por processos físicos (moagem, lavagem e secagem), foi submetida à uma deslignificação com $\mathrm{H}_{2} \mathrm{O}_{2}$ em meio alcalino e hidrólise. Após caracterização da biomassa lignocelulósica in natura e deslignificada observou-se remoção de 50\% da lignina. Foi quantificada a atividade enzimática da celulase de T. reesei e comercial Cellic ${ }^{\circledR}$ CTec2. Foram estudados $p H$ da reação, concentração de enzima e tempo de reação, obtendo-se pH ótimo 4,0 e 5,5 para a $T$. reesei e Cellic ${ }^{\circledR}$ CTec2, respectivamente. O maior rendimento em termos de concentração de enzima foi de $10 \mathrm{FPU} / \mathrm{g}$ de palha para ambas as enzimas e para o tempo, ambas enzimas apresentaram queda de conversão após 24 horas de hidrólise, possivelmente por contaminação microbiana. Por fim realizou-se o balanço material para a celulase comercial, projetando-se um rendimento do processo de hidrólise enzimática da palha de 23,8\%.
\end{abstract}

PALAVRAS-CHAVE: Etanol; Biomassa; Lignocelulósica; Hidrólise enzimática; Celulase.

\section{INTRODUÇÃO}

O setor energético é um dos setores de maior relevância para a economia mundial e a demanda pelo consumo de combustíveis como fonte de energia vem crescendo cada vez mais. Uma alternativa para a produção de energia renovável é através do uso de matériasprimas renováveis e os biocombustíveis, tais como bioetanol e biodiesel, são promissores para um desenvolvimento econômico sustentável (KOHLHEPP, 2010). O Brasil possui alto potencial de liderança mundial quando se trata de produção de biocombustíveis a partir de matérias-primas renováveis, devido à sua extensão territorial, condições climáticas, solo e potencial tecnológico, favoráveis para diversos agronegócios (KOHLHEPP, 2010).

O etanol de segunda geração (2G) é uma fonte de energia limpa, renovável e com menor impacto ambiental. O etanol de segunda geração é um biocombustível promissor uma vez que sua produção envolve como matéria-prima os materiais lignocelulósicos, biomassa mais abundante do planeta, sendo a palha e sabugo de milho, a palha de trigo, a palha e 
bagaço da cana de açúcar entre outros, matérias-primas não competitivas no mercado alimentício, mas sim resíduos da agroindústria e com baixo custo associado. No Brasil, com a utilização da colheita mecanizada na cultura da cana de açúcar resíduos como a palha da cana de açúcar tornaram-se favoráveis ao reaproveitamento para coprodução do etanol, diminuindo a dependência dos combustíveis fósseis. No Estado de São Paulo, o decreto estadual N. 47.700 de 11 março de 2003, prevê que até 2021 toda a colheita da cana seja mecanizada, eliminando as queimadas (NOVACANA, 2013).

\subsection{Materiais Lignocelulósicos}

Define-se biomassa como sendo todo recurso renovável que provém de matéria orgânica, vegetal ou animal, utilizado para produção de energia e produtos químicos. Os materiais lignocelulósicos que dão origem ao etanol são chamados comumente de biomassa lignocelulósica e são majoritariamente compostos por lignina, celulose e hemicelulose. A composição química da biomassa lignocelulósica, geralmente contém: 35-50\% de celulose, seguido de $20-35 \%$ de hemicelulose, $10-25 \%$ de lignina e uma pequena quantidade de cinzas e extrativos (SANTOS et al., 2012).

Os materiais lignocelulósicos representam cerca de metade da biomassa no planeta Terra, ou seja, $50 \%$ da matéria orgânica em nossa biosfera é constituída por biomassa lignocelulósica. Tais materiais tem o potencial de aplicação para a produção de energia (térmica e eletricidade) e de biocombustíveis, já que são renováveis e de baixo custo. Dentre os substratos lignocelulósicos mais gerados nos dias atuais estão em destaque: a palha e o bagaço da cana, sabugo e palha de milho, palhas de trigo e arroz, entre outros. A fração lignocelulósica dos materiais citados acima refere-se à parte que constitui a parede celular dos vegetais, a qual é responsável por dar firmeza às suas estruturas. É composta por uma matriz fibrosa, onde a lignina, uma macromolécula cuja estrutura tem natureza aromática, envolve as fibras flexíveis (celulose, hemicelulose e pectina) (SANTOS et al., 2012).

Estes materiais necessitam de um pré-tratamento físico, mecânico e/ou químico de deslignificação para a obtenção do etanol, através da sacarificação e fermentação (SILVA, 2009). A etapa de pré-tratamento desta biomassa tem a finalidade de separar a lignina da celulose e da hemicelulose, uma vez que a área superficial da lignina torna a biomassa praticamente inacessível e resistente à ação de enzimas e ao ataque de ácido. Através de um pré-tratamento eficaz a estrutura cristalina da matriz lignocelulósica é modificada, promovendo uma maior porosidade do material e diminuindo sua cristalinidade, possibilitando um maior acesso das enzimas ou ataque ácido à celulose (SUN; CHENG, 2002; SANTOS et al., 2012).

\subsection{Hidrólise Enzimática}

O processo de produção de etanol de segunda geração requer a hidrólise da celulose e da hemicelulose, que são os polissacarídeos presentes na biomassa lignocelulósica, o que pode ser realizado com o emprego de ácidos ou enzimas para que haja liberação de açúcares fermentescíveis. A hidrólise pode ser realizada por diferentes métodos, tais como: a hidrólise ácida que utiliza ácidos minerais concentrados (concentração maior do que 5\%) ou diluídos (concentração menor do que 5\%), ou a hidrólise enzimática com enzimas celulolíticas que 
atuam sinergicamente em diferentes sítios da cadeia celulósica (ADEN et al., 2002; SUN; CHENG, 2002).

A principal diferença entre a hidrólise ácida e a enzimática está no catalisador. Na hidrolise ácida, pelo fato do ácido mineral ser um catalisador não específico, é essencial o controle da reação para não levar a reações paralelas indesejáveis. Entretanto, na hidrólise enzimática, pelas enzimas serem catalisadores de elevada especificidade as reações secundárias não ocorrem, o que se torna uma grande vantagem (BON et al., 2008). Em outras palavras, a enzima tem a particularidade de promover reações muito específicas no meio, com o máximo de eficiência, no entanto, o ataque é muito mais lento. Além disso, a biocatálise é muito mais sensível à ação dos inibidores de reação, consequentemente o processo requer uma tecnologia mais complexa.

No processo de degradação da celulose, os microrganismos celulolíticos produzem uma mistura complexa de enzimas, chamadas de celulases. Estas enzimas, que coletivamente apresentam especificidade para as ligações glicosídicas $\beta-1,4$, são necessárias para a solubilização completa da celulose, mesmo das regiões cristalinas, existindo sinergismo na sua forma de atuar. Tradicionalmente, dependendo do seu sítio de ação na celulose, elas têm sido divididas em dois grupos: as endoglucanases (EG) e as exoglucanases/celobio-hidrolases $(\mathrm{CBH})$. As endoglucanases (1,4- $\beta$-D-glican-4-glicano-hidrolase, EC 3.3.1.4) hidrolisam randomicamente regiões internas na molécula da celulose, tendo mais afinidade pelas regiões amorfas, produzindo celo-oligossacarídeos com diversos graus de polimerização, que serão atacados pelas exoglucanases. Da sua ação, que envolve o consumo de uma molécula de água, resulta um novo terminal redutor e um novo terminal não redutor (BON et al., 2008).

As exoglucanases são formadas pela celodextrinase (1,4- $\beta$-D-glicana-glicano-hidrolase, EC 3.2.1.74), e pela celobio-hidrolase ( $\mathrm{CBH}$ - 1,4- $\beta$-D-glicana-celobio-hidrolases, EC 3.2.1.91). A CBH pode ser dividida em dois tipos: $\mathrm{CBH}$ I e $\mathrm{CBH}$ II. As enzimas do tipo I ( $\mathrm{CBH}$ I) hidrolisam terminais redutores, enquanto que as do tipo II (CBH II) hidrolisam terminais não redutores. As $\mathrm{CBH}$ apresentam em sua estrutura uma região responsável pela ligação da molécula ao substrato e sofrem inibição pelo seu produto de hidrólise, a celobiose (AWAFO et al., 1998).

Completando a degradação da celulose à glicose, a celobiose, dissacarídeo solúvel em água, e potente inibidor de muitas celulases, é hidrolisada em duas moléculas de glicose pela enzima celobiase ( $\beta$-glicosidase ou $\beta$-glicosídeo glico-hidrolases, EC 3.2.1.21). O nível de atividade da celobiase nas preparações de celulases é crítico, não apenas para evitar a inibição das celulases, como também para finalizar a degradação completa da celulose em glicose, fundamental para a produção de etanol em biomassa. É também reportada que a celobiase sofre inibição pelo seu produto de hidrólise, a glicose (AWAFO et al., 1998; LYND et al., 2002). A reação sinérgica ocorre como um resultado da ação sequencial, cooperativa entre os componentes do complexo celulolítico, em que o produto de uma reação enzimática torna-se o substrato para o outro (LYND et al., 2002).

Um dos microrganismos celulolíticos mais extensivamente estudados é o fungo filamentoso do gênero Trichoderma e especialmente as espécies de $T$. reesei e $T$. longibrachiatum, que também são usados industrialmente para a produção da celulase. $\mathrm{O}$ sistema celulósico extracelular de $T$. reesei é composto de 60 a $80 \%$ de exoglucanases ou 
celobiohidrolases, 20 a $36 \%$ de endoglucanases, e $1 \%$ de $\beta$-glicosidases (SUN; CHENG, 2002). A espécie T. reesei foi melhorada ao longo dos anos, por mutagênese aleatória, o que resultou no aumento da produtividade substancial da enzima (LI et al., 2016). T. reesei RUT C-30 é uma cepa que fornece alto rendimento e é comercialmente usada na atualidade. Com o advento de novas fronteiras no campo da biotecnologia, celulases têm atraído muito interesse científico, por causa da diversidade de suas aplicações, e também para aumentar a compreensão do mecanismo de hidrólise enzimática (LI et al., 2016).

Para hidrólise enzimática, muitas pesquisas estão sendo realizadas no sentido de viabilizar economicamente o uso de celulases na produção de etanol. Um exemplo é a Cellic ${ }^{\circledR}$ CTec2 que é uma enzima comercial produzida pela empresa Novozymes para a produção de etanol celulósico. É um biocatalisador concentrado, que contém um complexo de enzimas formulado para melhorar o desempenho do biocatalisador e reduzir a dosagem requerida para a conversão da celulose em açúcares fermentescíveis. Devido ao elevado teor de $\beta$-glicosidase, enzima que permite a conversão final da celobiose em glicose, o produto proporciona melhor desempenho ao hidrolisar substratos lignocelulósicos pré-tratados com maiores quantidades de sólidos totais.

Neste trabalho estudou-se a hidrólise enzimática da palha de cana de açúcar para a obtenção de açúcares fermentescíveis para a produção de etanol de segunda geração. Foram estudadas as condições de hidrólise: $\mathrm{pH}$, quantidade de biocatalisador e tempo de reação; para duas celulases, uma purificada de T.reesei e uma comercial, Cellic ${ }^{\circledR}$ CTec2. Desenvolveu-se também um balanço material para cálculo do rendimento da etapa de hidrólise.

\section{MATERIAIS E MÉTODOS}

A palha de cana de açúcar, biomassa utilizada neste trabalho, foi coletada, lavada e moída em moinho de facas. Realizou-se a caracterização da biomassa lignocelulósica através da determinação do teor de cinzas totais, lignina Klason, holocelulose e celulose, antes e após pré-tratamento químico da palha de cana de açúcar com peróxido de hidrogênio alcalino. Os testes de caracterização foram realizados de acordo com método descrito em Morais et al. (2010).

Para a deslignificação foi utilizado o pré-tratamento químico com peróxido de hidrogênio alcalino (AZZAM, 1989). Foram pesadas $10 \mathrm{~g}$ de amostras de palha triturada e adicionados $250 \mathrm{~mL}$ de solução de peróxido de hidrogênio $2 \%$ em massa (proporção 1:25). Ajustou-se o pH da suspensão para 11,5 utilizando escamas de hidróxido de sódio. Posteriormente a mistura reacional foi agitada a $200 \mathrm{rpm}$, à temperatura de $30^{\circ} \mathrm{C}$ até completar 24 horas. Após esse período foi filtrada e o componente residual lavado até a água de lavagem apresentar $\mathrm{pH}$ neutro. Posteriormente, o material obtido permaneceu em estufa a $60^{\circ} \mathrm{C}$ até massa constante.

A partir da palha de cana deslignificada iniciou-se o estudo da hidrólise enzimática com as enzimas celulase Cellic ${ }^{\circledR}$ CTec2, Cellic ${ }^{\circledR}$ HTec, celulase de $T$. reesei e celulase de $T$. longibrachiatum. Analisou-se a atividade enzimática das enzimas através do método de determinação da atividade de papel de filtro - FPU (Filter Paper Activity), proposto por Ghose (1987), e apenas as celulases que apresentaram melhor desempenho seguiram para os 
estudos de $\mathrm{pH}$, concentração de enzima e tempo de hidrólise. Para encontrar os valores de maior rendimento nos ensaios foram realizadas a determinação da concentração de açúcares redutores pelo método do DNS (MILLER, 1959) e da concentração de glicose pelo método enzimático (reativo enzimático LABTEST Glicose Liquiform® Ref.: 133).

Os ensaios de hidrólise foram realizados da seguinte forma: em um erlenmeyer de 250 $\mathrm{mL}$ foi pesado $5 \mathrm{~g}$ de palha deslignificada e adicionou-se a quantidade de enzima que forneceu a atividade desejada (10 FPU/grama de palha para os ensaios de $\mathrm{pH}$ e tempo de reação e variável para os ensaios de concentração de enzima). Adicionou-se $100 \mathrm{~mL}$ de solução tampão citrato de sódio $50 \mathrm{mM}$ ou fosfato de sódio $50 \mathrm{mM}$, dependendo do $\mathrm{pH} \mathrm{em}$ estudo. Então esta mistura foi levada a um incubador rotativo onde ficou durante 48 horas reagindo a $45^{\circ} \mathrm{C}$, numa rotação de $150 \mathrm{rpm}$. Após este período, filtrou-se a mistura, o resíduo foi levado à estufa por 24 horas e $60^{\circ} \mathrm{C}$ e pesado e o filtrado seguiu para posterior quantificação dos açúcares formados.

\section{RESULTADOS E DISCUSSÃO}

Para a caracterização da biomassa lignocelulósica após a deslignificação foi realizada a quantificação dos teores de cinzas totais e lignina Klason. Determinou-se para a palha de cana de açúcar in natura um teor de lignina de $16,99 \pm 0,33 \%(\mathrm{~m} / \mathrm{m})$. Após o pré-tratamento com peróxido de hidrogênio alcalino o teor de lignina da biomassa foi reduzido para 8,6 \pm $0,35 \%(\mathrm{~m} / \mathrm{m})$. Esta quantificação permitiu verificar a eficácia do pré-tratamento utilizado, que resultou numa redução de cerca de $50 \%$ do teor de lignina presente na palha da cana de açúcar. Vale salientar que o pré-tratamento é necessário para proporcionar maior acessibilidade das enzimas à fibra celulósica, pela redução do teor de lignina que dificulta o acesso das enzimas à celulose, assim como por mudanças estruturais da fibra, como redução da cristalinidade (SUN; CHENG, 2002).

Foram realizadas determinações da atividade enzimática de quatro complexos enzimáticos contendo celulase: celulase de Trichoderma reesei, celulase de Trichoderma longibrachiatum, celulase comercial Cellic ${ }^{\circledR}$ CTec2 e celulase comercial Cellic ${ }^{\circledR}$ HTec, ambas da empresa Novozymes. A atividade enzimática foi expressa em FPU - Unidade de Papel de Filtro (Filter Paper Unit), seguindo o método proposto por Ghose (1987).

Foi necessário a realização da medida da atividade enzimática das enzimas antes de seu uso, para padronizar a quantidade de enzima utilizada nas reações, em termos de atividade enzimática e não em sua massa, pois os biocatalisadores podem diferir entre si em relação à pureza, teor de proteína total, grau de desnaturação e presença de suporte de imobilização. Na Tabela 1 encontram-se os resultados obtidos de atividade enzimática FPU das enzimas celulolíticas estudadas.

O estudo da hidrólise enzimática para a palha de cana deslignificada foi realizada com duas celulases, escolhidas através do critério de maior atividade, sendo uma purificada, a celulase de Trichoderma reesei e uma celulase comercial Cellic ${ }^{\circledR}$ CTec2 , que apresentaram uma atividade enzimática de 960 FPU/g enzima e 307 FPU/g enzima, respectivamente. Para o estudo das condições de reação que resultam num melhor desempenho da hidrólise enzimática da palha da cana deslignificada foram escolhidas três variáveis: $\mathrm{pH}$, concentração de enzima e tempo de hidrólise. Para avaliar a eficiência da hidrólise foram quantificados os 
açúcares fermentescíveis liberados durante o tempo de reação, tais como glicose e açúcares redutores totais (AR).

Tabela 1 - Atividade enzimática das celulases estudadas.

\begin{tabular}{cccc}
\hline Enzima & $\begin{array}{c}\text { Solução Enzima } \\
(\mathbf{g} / \mathbf{L})\end{array}$ & $\begin{array}{c}\text { Atividade } \\
(\text { FPU/mLsolução) }\end{array}$ & $\begin{array}{c}\text { Atividade } \\
\text { (FPU/genzima) }\end{array}$ \\
\hline T. reesei & 1,0 & 0,96 & 960 \\
T. longibrachiatum & 1,0 & 0,52 & 520 \\
Cellic® CTec2 & 1,5 & 0,46 & 307 \\
Cellic® HTec2 & 3,0 & 0,41 & 137 \\
\hline
\end{tabular}

$\mathrm{O}$ estudo do $\mathrm{pH}$ foi realizado com condições reacionais de 48 horas, $45^{\circ} \mathrm{C}$ e $10 \mathrm{FPU} / \mathrm{g}$ de palha deslignificada. As concentrações de açúcares fermentescíveis liberadas foram quantificadas a fim de determinar o valor do $\mathrm{pH}$ ótimo para este substrato, como é apresentado na Figura1 para a reação com celulase de T. reesei e na Figura 2 para a celulase Cellic $®$ CTec2 .

Analisando-se o perfil da Figura 1 pode-se determinar que o pH ótimo, onde há a maior liberação de açúcares fermentescíveis, para a celulase de T.reesei, é o pH 4,0, tanto para a obtenção de maior quantidade de glicose $(4,65 \mathrm{~g} / \mathrm{L})$ como açúcares redutores $(4,98 \mathrm{~g} / \mathrm{L})$. Porém é possível observar que, afastando-se do $\mathrm{pH}$ 4,0 ocorre uma queda acentuada da concentração de açúcares produzidos e este efeito é mais acentuado para a liberação de glicose na hidrólise. Analisando-se o perfil da Figura 2 pode-se determinar que o $\mathrm{pH}$ ótimo, da celulase Cellic ${ }^{\circledR}$ CTec 2 é o pH 5,5. Segundo os dados da empresa Novozymes, empresa produtora da Cellic ${ }^{\circledR} \mathrm{CTec} 2$, o pH ótimo de trabalho desta enzima está na faixa entre 5,0 e 5,5 , em uma temperatura teste de $50^{\circ} \mathrm{C}$ e 72 horas de reação.

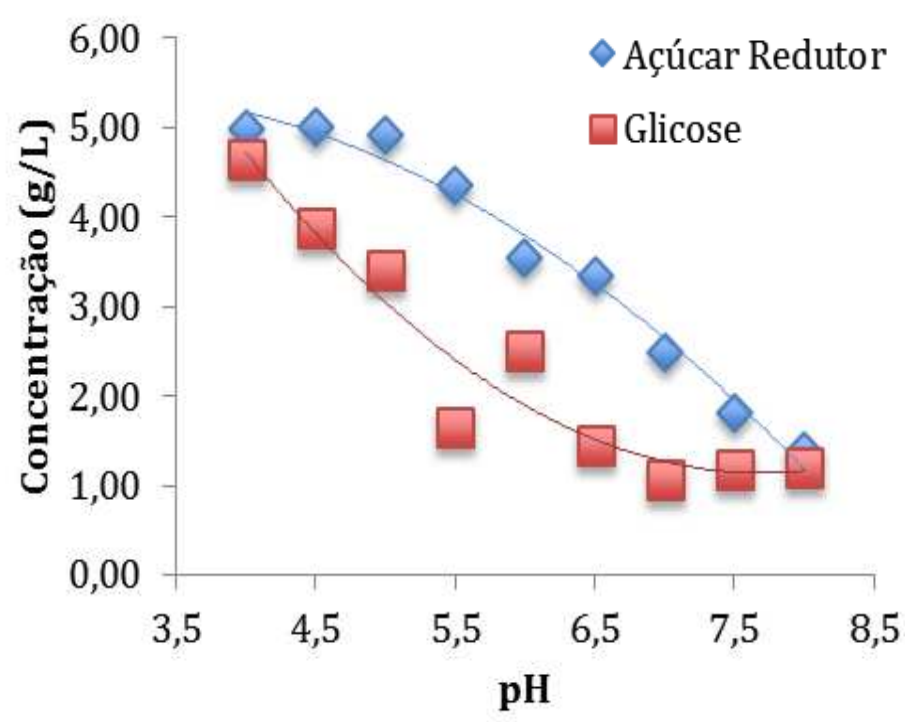

Figura 1 - Concentração de açúcares fermentescíveis liberados na hidrólise enzimática com a celulase de T.reesei em diferentes valores de $\mathrm{pH}$. 


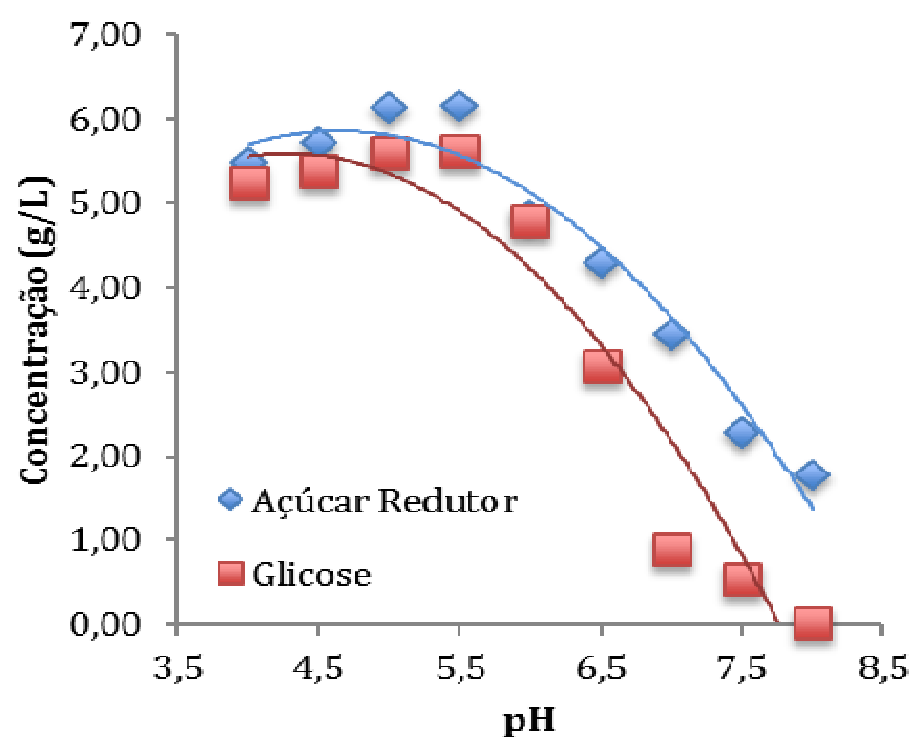

Figura 2 - Concentração de açúcares fermentescíveis liberados na hidrólise enzimática com a celulase comercial Cellic ${ }^{\circledR}$ CTec2 em diferentes valores de $\mathrm{pH}$.

Diferente do que ocorreu com a celulase de T. reesei, para a Cellic ${ }^{\circledR}$ CTec2 os valores de pH ótimo se mantêm em uma faixa de operação de pH de 4,0 a 5,5, com liberação de 5,5 a $6,2 \mathrm{~g} / \mathrm{L}$ de açúcares redutores e 5,2 a 5,6 g/L de glicose nesta faixa. Isto a torna interessante em uso industrial, pois em um biorreator de alta capacidade torna-se difícil a manutenção de condições homogêneas em todo o reator. Neste caso uma faixa larga de valores de $\mathrm{pH}$ ótimo não acarreta perda de eficiência por pequenas variações de $\mathrm{pH}$.

Outra diferença entre o comportamento da atividade das celulases purificada e comercial em função do $\mathrm{pH}$ é que, a primeira apresenta um distanciamento entre as curvas de açúcar redutor e glicose, mostrando que há uma grande conversão de celulose em oligômeros (tais como celobiose, celotrioses, etc.), que são açúcares redutores, devido à presença de endo e exoglucanases. Porém nem todo o açúcar redutor é transformado em glicose, pela pequena quantidade de $\beta$-glicosidase, fração celulolítica que converte os oligômeros em glicose, no complexo celulolítico purificado. A celulase Cellic ${ }^{\circledR}$ CTec2, por ser uma enzima comercial, possui em sua formulação as frações celulolíticas necessárias, em quantidades proporcionais, viabilizando uma liberação de glicose e açúcares redutores em quantidades equivalentes, principalmente na faixa de $\mathrm{pH}$ indicada pelo fornecedor; 5,0 a 5,5. Isto pode ser observado na curva apresentada na Figura 2, que mostra que a curva de glicose e açúcares redutores caminham juntas, ou seja, são formados oligômeros e estes convertidos em glicose quase simultaneamente.

O estudo da quantidade de enzima usada para a hidrólise, expressa em FPU/g de palha de cana (biomassa), foi realizado em condições reacionais de 48 horas, $45^{\circ} \mathrm{C}$ e pH ótimo de cada enzima. As concentrações das celulases estudadas, a fim de determinar a concentração de enzima em que houvesse uma maior liberação de açúcares fermentescíveis, foram: 1; 2,5; 5; 10 e 20 FPU/g substrato. A Figura 3 apresenta o perfil de açúcares formado pela hidrólise da biomassa com celulase de T.reesei e a Figura 4 com Cellic ${ }^{\circledR}$ CTec2 2 , respectivamente. 


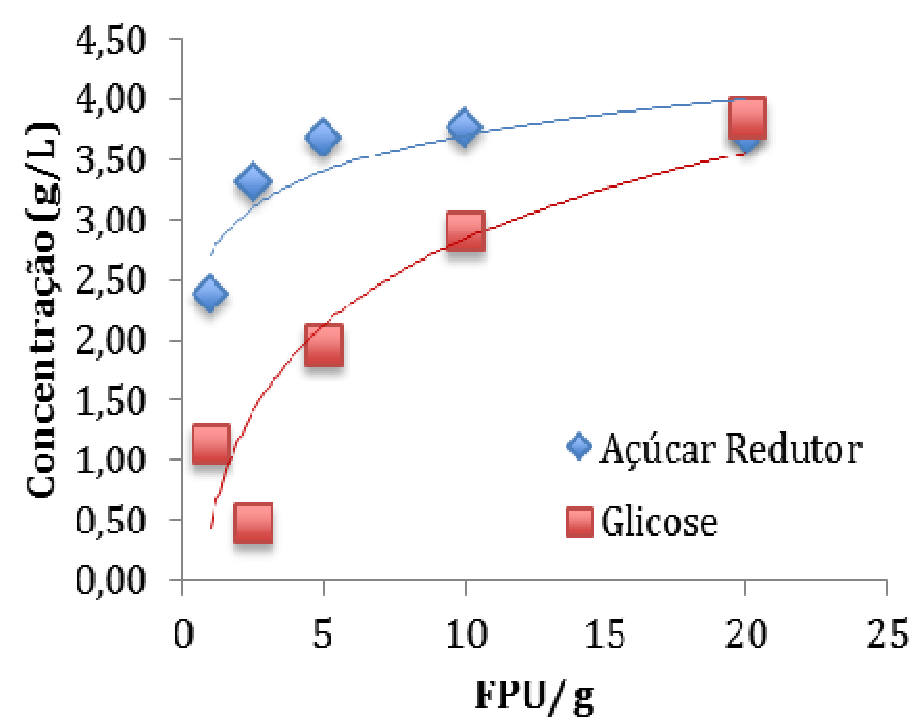

Figura 3 - Concentração de açúcares fermentescíveis liberados em função de quantidade de enzima celulase de $T$. reesei.

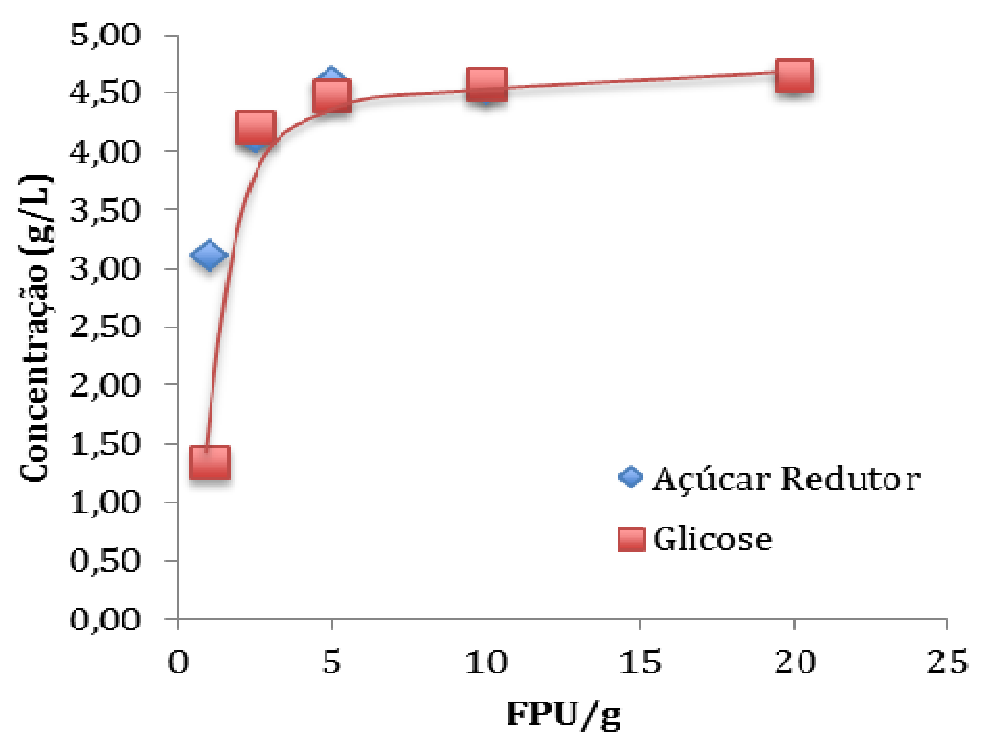

Figura 4 - Concentração de açúcares fermentescíveis liberados em função de quantidade de enzima da celulase Cellic ${ }^{\circledR}$ CTec2.

As concentrações de enzima que liberaram a maior concentração de açúcares foram de $20 \mathrm{FPU} / \mathrm{g}$ de palha deslignificada e $10 \mathrm{FPU} / \mathrm{g}$ de palha deslignificada para as enzimas de $T$. reesei e Cellic $\AA$ CTec 2 , respectivamente. A Figura 3 também mostra que a enzima comercial Cellic ${ }^{\circledR}$ CTec 2 tem um desempenho superior na hidrólise, pois as curvas de açúcares redutores e glicose se sobrepõem, como também mostra a Figura 2. Isso significa que o complexo enzimático desta enzima é rico em $\beta$-glicosidase, o que leva rapidamente os oligossacarídeos formados pela hidrólise da celulose, tais como celobiose, em glicose, minimizando a inibição da celobiohidrolase pelo acúmulo de celobiose (SUN; CHENG, 2002). 
O estudo do tempo de reação está apresentado na Tabela 2 e o melhor resultado obtido para a sacarificação com ambas as celulases estudadas foi para o tempo de 24 horas. Os resultados mostram que ocorreu redução no teor de glicose após 24 horas de hidrólise e acredita-se que isto ocorreu devido à presença de microrganismos contaminantes, uma vez que os ensaios não foram realizados em ambiente estéril. Os resultados mostram que para tempos de reação longos seria necessário a adição de agentes microbicidas.

Tabela 2 - Concentração de glicose obtida ao longo do tempo de hidrólise.

\begin{tabular}{ccc}
\hline \multirow{2}{*}{ Tempo $(\mathbf{h})$} & \multicolumn{2}{c}{ Glicose $(\mathrm{g} / \mathrm{L})$} \\
\cline { 2 - 3 } & Celulase T.reesei & Celulase Cellic ${ }^{\circledR}$ CTec2 \\
\hline 2 & 0,51 & 0,60 \\
4 & 0,72 & 0,66 \\
8 & 0,91 & 1,38 \\
24 & 3,27 & 2,75 \\
48 & 3,04 & 1,92 \\
72 & 2,46 & 1,08 \\
\hline
\end{tabular}

\subsection{BALANÇO MATERIAL}

Foi proposto um balanço material com base nos resultados obtidos em escala laboratorial com a celulase comercial Cellic ${ }^{\circledR} \mathrm{CTec} 2$, que apresentou melhor performance quanto à liberação de açúcares fermentescíveis. O processo de obtenção do hidrolisado enzimático da palha da cana de açúcar envolveu etapas de preparação da biomassa, deslignificação com peróxido em meio alcalino e a etapa de hidrólise enzimática, conforme descrito na Figura 5. As condições reacionais de maior rendimento apresentadas pela celulase Cellic® CTec2, são as seguintes: $\mathrm{pH}$ 5,5; 2,5 FPU/grama de palha deslignificada e tempo reacional de 24 horas. A Tabela 3 sumariza os valores das correntes que estão apresentadas no diagrama de blocos da Figura 5.

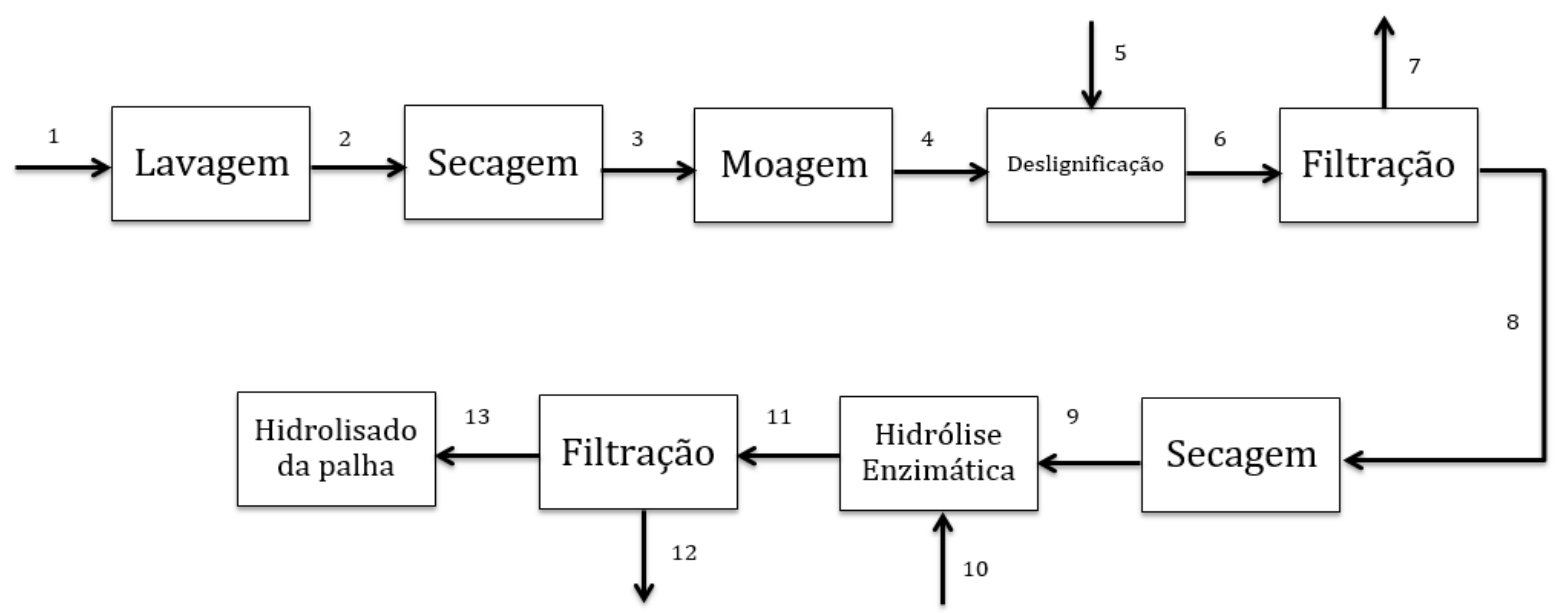

Figura 5 - Diagrama de blocos do processo proposto de pré-tratamento e hidrólise enzimática da palha de cana de açúcar. 
Tabela 3 - Correntes do diagrama de blocos do processo proposto de de pré-tratamento e hidrólise enzimática da palha de cana de açúcar.

\begin{tabular}{|c|c|c|c|}
\hline Corrente & Componentes & Quantidade & Unidade \\
\hline 1 & Palha in natura & 1000,0 & $\mathrm{~kg} \cdot \mathrm{dia}^{-1}$ \\
\hline 2 & Palha úmida & ND & - \\
\hline 3 & Palha seca & 908,7 & $\mathrm{~kg} \cdot \mathrm{dia}^{-1}$ \\
\hline 4 & Palha seca moída & 908,7 & $\mathrm{~kg} \cdot \mathrm{dia}^{-1}$ \\
\hline 5 & Solução de $\mathrm{H}_{2} \mathrm{O}_{2} 2 \%$ pH 11 & 22,7 & $\mathrm{~m}^{3} \cdot \mathrm{dia}^{-1}$ \\
\hline 6 & Biomassa deslignificada + peróxido & ND & - \\
\hline 7 & Resíduo pós-deslignificação (base seca) & 229,5 & $\mathrm{~kg} \cdot \mathrm{dia}^{-1}$ \\
\hline 8 & Biomassa deslignificada úmida & ND & - \\
\hline 9 & Biomassa deslignificada seca & 679,2 & $\mathrm{~kg} \cdot \mathrm{dia}^{-1}$ \\
\hline 10 & Solução enzima CellicCTec® pH5,5 & 13,6 & $\mathrm{~m}^{3} \cdot \mathrm{dia}^{-1}$ \\
\hline 11 & Hidrolisado enzimático + resíduo sólido & ND & - \\
\hline 12 & Resíduo sólido (base seca) & 502,6 & $\mathrm{~kg} \cdot \mathrm{dia}^{-1}$ \\
\hline 13 & Hidrolisado enzimático $\left(4,21 \mathrm{~kg} / \mathrm{m}^{3}\right.$ de glicose $)$ & 13,6 & $\mathrm{~m}^{3} \cdot \mathrm{dia}^{-1}$ \\
\hline
\end{tabular}

A etapa de preparação da biomassa consiste em processos físicos tais como lavagem, secagem e moagem. O percentual de umidade que permanece na biomassa após lavagem e secagem é de 9,13\%, permitindo-nos avaliar a projeção em escala industrial com base na massa seca de biomassa. Admite-se como base de cálculo $1.000 \mathrm{~kg} / \mathrm{dia}$ de palha de cana em base úmida, e consequentemente o processo se inicia com 908,7 kg/dia de biomassa seca. Admite-se ainda que nesta primeira etapa de preparação da biomassa não há perda de material. A etapa de deslignificação é realizada com $\mathrm{H}_{2} \mathrm{O}_{2}$ a $2 \%$ em meio alcalino, sendo necessários 22,7 $\mathrm{m}^{3}$ de solução. Ao final deste processo há dissolução de $25,26 \%$ da biomassa inicialmente alimentada. Desta forma a biomassa que continua no processo é 679,2 $\mathrm{kg}$ de palha deslignificada seca.

$\mathrm{Na}$ etapa de hidrólise enzimática foi utilizada solução tampão $\mathrm{pH} 5,5$ contendo $2,5 \times 10^{3}$ FPU/kg de biomassa, num volume de tampão acetato de sódio $\mathrm{pH} 5,5 \mathrm{de} 13,6 \mathrm{~m}^{3}$. Isso representa um consumo de enzima de $5,53 \mathrm{~kg}$ de enzima Cellic® Ctec 2 a cada batelada diária. Após o tempo reacional, a carga do reator foi enviada para separação a fim de retirar o resíduo sólido do hidrolisado da palha da cana de açúcar. O resíduo sólido retirado equivale a $74 \%$ da massa de palha deslignificada que entra nesta etapa do processo, $502,6 \mathrm{~kg}$. Considera-se que toda a solução que passa pela filtração é recuperada, obtendo-se assim o mesmo volume de entrada de $13,6 \mathrm{~m}^{3} /$ dia de solução hidrolisada. Nesta solução estão contidos os açúcares gerados através do processo de hidrólise enzimática.

O cálculo do rendimento do processo foi baseado na concentração de glicose liberada obtida experimentalmente, de $4,21 \mathrm{~kg} / \mathrm{m}^{3}$, o que resulta na obtenção de $57,17 \mathrm{~kg} / \mathrm{dia}$ de glicose na corrente final de hidrolisado. $\mathrm{O}$ rendimento da etapa de hidrólise é baseado na quantidade de glicose formada a partir da celulose disponível na biomassa no início do processo. Considerando que foi obtido para a biomassa deslignificada um teor de celulose de $35,29 \%$, foi obtido então um rendimento de $23,8 \%$ da conversão da celulose presente na biomassa deslignificada em glicose. 


\section{CONCLUSÃO}

Estudou-se neste trabalho a sacarificação da palha de cana de açúcar para a produção de etanol de segunda geração a partir da biomassa lignocelulósica, dando enfoque ao estudo da hidrólise enzimática, usando tanto enzimas purificadas quanto enzimas comerciais. Comparando-se os resultados das enzimas testadas, celulase de $T$. reesei e celulase comercial Cellic ${ }$ CTec2, a enzima que apresentou resultados mais satisfatórios foi a Cellic ${ }^{\circledR}$ CTec2, uma vez que este complexo enzimático é preparado para aplicação industrial, e as quantidades de endoglucanase, exoglucanase e $\beta$-glicosidase apresentam um equilíbrio para que a liberação de açúcares redutores e glicose ocorram simultaneamente. A melhor condição de uso da celulase comercial Cellic ${ }^{\circledR}$ CTec 2 nas condições de $45^{\circ} \mathrm{C}$ e $150 \mathrm{rpm}$ de agitação foi $\mathrm{pH} 5,5 ; 2,5 \mathrm{FPU} / \mathrm{g}$ substrato e 24 horas de reação. Com estas condições calculou-se o rendimento da etapa de hidrólise enzimática em $23,8 \%$ de conversão da celulose da biomassa em glicose.

\section{AGRADECIMENTOS}

Ao Centro Universitário FEI pelo suporte para o desenvolvimento do trabalho.

\section{REFERÊNCIAS}

ADEN, A., RUTH, M.; IBSEN, K.; JECHURA, J.; NEEVES, K.; SHEEHAN, J.; WALLACE, B.; MONTAGUE, L.; SLAYTON, A.; LUKAS, J. Lignocellulosic Biomass to ethanol process design and economics utilizing co-current dilute acid prehydrolysis and enzymatic hydrolysis for corn stover. NREL/TP-510-32438. Golden, CO: NREL-National Renewable Energy Laboratory, June 2002.

AWAFO, V.A.; CHAHAL, D.S.; SIMPSON, B.K.. Optimization of ethanol production by Saccharomyces cerevisiae (ATCC 60868) and Pichia stipitis y-7124: a response surface model for simultaneous hydrolysis and fermentation of wheat straw. Journal of Food Biochemistry,v. 22, n. 6, p.489-509, 1998. Disponível em: $<$ http://dx.doi.org/10.1111/j.1745-4514.1998.tb00258.x.>. Acesso em: 10 dez.2015.

AZZAM, A. M. Pretreatment of cane bagasse with hydrogen peroxide for enzymatic hydrolysis of cellulose and ethanol fermentation. Journal of Environmental Science and Health B, p.421-423,1989 (DOI: 10.1080/03601238909372658).

BON, E. P. S; FERREIRA, M. A.; CORVO, M. L. Enzimas em Biotecnologia: produção aplicação e mercado. Rio de Janeiro: Interciência Ltda., 2008.

GHOSE, T. K. Measurement of cellulase activities. Pure and Applied Chemistry. Grã Bretanha, International Union of Pure and Applied Chemistry, v. 59, n. 2, p. $257-268$, 1987. Disponível em: < https://www.iupac.org/publications/pac2007/1987/pdf/5902x0257.pdf>. Acesso em: 25 abr. 2016.

KOHLHEPP, G. Análise da situação da produção de etanol e biodiesel no Brasil. Estudos Avançados, v. 24, n.68, p.223-253,2010.

LI, Y.; LIU, C.; BAI, F.; ZHAO, X. Overproduction of cellulase by Trichoderma reesei RUT C30 through batch-feeding of synthesized low-cost sugar mixture. Bioresource Technology, v. 216, p.503-510, 2016. Disponível em:<http://dx.doi.org/10.1016/j.biortech.2016.05.108>. Acesso em: 18 fev.2017. 
LYND, L. R; WEIMER P. J; VAN ZYL., W. H.; PRETORIUS, I. S. Microbial cellulose utilization: funtamentals and biotechnology. Microbiology and Molecular Biology Reviews, v.66, n.3, p.506-577, 2002.

MILLER, G. L. Use of dinitrosalicylic acid reagent for determination of reducing sugar. Analytical Chemistry, p.426-428, $1959 . \quad$ Disponível em: $<$ http://pubs.acs.org/doi/abs/10.1021/ac60147a030>. Acesso em 27 jul. 2015.

MORAIS, J.P.S.; ROSA, M.F.; MARCONCINI, J.M. Procedimentos para análise lignocelulósica. Campina Grande, PB: Embrapa Algodão, 2010. p. 54. (Embrapa Algodão. Documentos, 236).

NOVACANA. A produção de cana-de-açúcar no Brasil (e no mundo). [S.I.]: 2013. Disponível em: <https://www.novacana.com/cana/producao-cana-de-acucar-brasil-emundo/>. Acesso em: 15 mar. 2016.

SANTOS, F.A.; QUEIRÓZ, J.H.; COLODETTE, J.L.; FERNANDES, S.A.; GUIMARÃES, V.M.; T. REZENDE, S.T. Potencial da palha de cana-de-açúcar para produção de etanol. Química Nova, v. 35, n. 5, p. 1004-1010, 13 jan 2012. Disponível em: < http://quimicanova.sbq.org.br/imagebank/pdf/Vol35No5_1004_24-RV11835_cor.pdf>. Acesso em: 08 maio 2016.

SUN, Y.; CHENG, J. Hydrolysis of lignocellulosic materials for ethanol production: a review. Bioresource Technology, v. 83, p.1-11, 2002.

\title{
STUDY OF ENZYMATIC HYDROLYSIS OF SUGAR CANE STRAW FOR THE PRODUCTION OF ETHANOL
}

\author{
A.C.LUCARINI ${ }^{1, *}$, A. C. T. DELQUIARO ${ }^{1}$, L. C. P. T. VIDOCA ${ }^{1}$, R. BRAZ ${ }^{1}$, R. M. \\ MARTINS $^{1}$, T. P. ALVES ${ }^{1}$ \\ ${ }^{1}$ Centro Universitário FEI, Departamento de Engenharia Química \\ EE-mail: lucarini@fei.edu.br
}

\begin{abstract}
It was studied the enzymatic hydrolysis of sugarcane straw in order to obtain fermentable sugars. The biomass passed through physical processes (milling, washing and drying), delignification with $\mathrm{H}_{2} \mathrm{O}_{2}$ alkaline and hydrolysis. After characterization of the lignocellulosic biomass in natura and delignified it was observed the removal of $50 \%$ of the lignin content. The enzymatic activity of $T$. reesei cellulase and commercial Cellic ${ }^{\circledR}$ CTec 2 was quantified. The reaction $\mathrm{pH}$, enzyme concentration and reaction time were studied, obtaining optimum $\mathrm{pH} 4.0$ and 5.5 for $T$. reesei and Cellic ${ }_{\circledR}$ CTec2, respectively. The highest yield in terms of enzyme concentration was $10 \mathrm{FPU} / g$ of straw for both enzymes and for the time, both enzymes reduced conversion after 24 hours of hydrolysis, possibly due to microbial contamination. Finally, it has been carried out a material balance for the commercial cellulase, resulting in a yield of the enzymatic hydrolysis of the cellulose content of $23.8 \%$.
\end{abstract}

KEYWORDS: Ethanol; Biomass; Lignocellulosics; Enzymatic Hydrolisis; Cellulase. 